\title{
Therapeutic Guidelines: Neurology. Version 5
}

Melbourne: Therapeutic Guidelines Limited; 2017. 209 pages

Also available at www.tg.org.au

This edition is packed full of useful and current information presented in a concise and easy-toread format. All the major topics are covered by experts in the field and supplemented with tables, illustrations and flow diagrams to help make management easier.

It includes the new seizure classification, current stroke guidelines, as well as differentiation of peripheral versus central dizziness. I particularly like the headache and facial pain chapter. Headaches are a complex area with many subtypes, all with their own treatments. As there is no single treatment option for headaches, guidelines like these are needed to demystify the syndromes and treatment options.

The multiple sclerosis chapter offers a helpful two-page table summarising the immunotherapy options, their adverse effects and disease efficacy. Since the publication of this book, there has been another new antibody, ocrelizumab, approved for relapsing remitting multiple sclerosis and the first ever treatment for primary progressive multiple sclerosis. I am sure this will be in the next edition. I note however, that the multiple sclerosis drugs have not been included in the pregnancy and breastfeeding table at the back of the book, which I think would be beneficial.

In the movement disorder section, I was particularly pleased to see a section on how to manage Parkinson's disease in patients who are nil by mouth for a short period of time. I also liked the conversion table for rotigotine patches.

I would highly recommend this edition to all doctors looking for an accurate, quick reference guide centred around Australian practice.

Camilla Jozwik attended a Sanofi Genzyme multiple sclerosis leadership summit in Sydney last year. The flights, accommodation and food were fully paid for by Sanofi Genzyme.

\section{Camilla Jozwik}

Neurology advanced trainee, Liverpool Hospital, Sydney

Aust Prescr 2018;41:123 https://doi.org/10.18773/ austprescr.2018.038

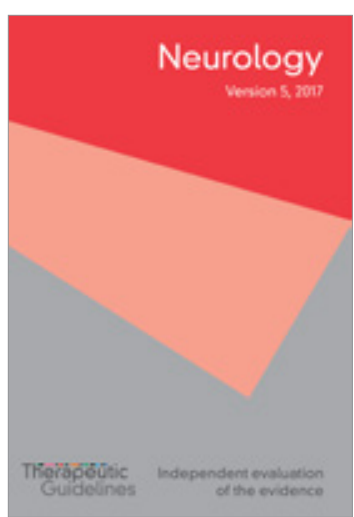

